\title{
A Storehouse of Life Diversity in The Mango Season
}

Anvar P A

M.Phil.

Department of English

Sree Narayana Guru College

Coimbatore, Tamil Nadu, India

anvarpkd001@gmail.com

Dr. A.J Manju

Associate Professor and Head

M.A., M.Phil., Ph.D., B.Ed.,

Sree Narayana Guru College

Coimbatore, Tamil Nadu, India

manjumadhu57@gmail.com

DOI: https://doi.org/10.24113/ijellh.v9i4.10990

\begin{abstract}
There are many types of religions and beliefs in India. There have been many works based on such variations. It is such an important novel based on Indian culture called The Mango Season written by Amulya Malladi. The main focus of this novel is on the Brahmin system and the framework it exemplifies. The essence of this story is a girl who is born and raised according to the Brahmin faith and the events that take place around it. The story is written by taking the ideas of this theme as a writer and pointing out this character on many levels. Therefore, while reading this story, a variety of needs and suggestions may come out from
\end{abstract}


the readers. The protagonist of the story is a girl named Priya who takes the story forward in many perspectives and ideas. AmulyaMalladi tells her to the readers about the changes that take place when she goes to the America for higher studies and stays away from Indian culture, as well as a tendency to adapt to the American tradition. As a girl growing in India and living in the United States, there have been a lot of changes showed up through this story. 
Indian writer Amulya Malladi's novel The Mango Season (2003) is thereview over the format of a few days in Hyderabad in India. The story maintains Priya Rao, a twenty-sevenyear-old Indian woman who returned back to her home place during the summertime in Mango Season but she has major problem and worries. Having life in America for the past seven years, Priya is worried to disclose her traditional Brahmin family the one secret she is hiding from them all the time: she is connected and getting married to an American man. Going through the whirlwind of ancient customs and rituals, deeply rooted prejudices, familiar caste systems, local culinary recipes, the full embodiment of Indian tradition, Priya must have the courage to tell the truth to her family. Mango Season is Malladi's second novel since the release of A Breath of Fresh Air in 2002, which explores themes of family, identity, nostalgia, marriage, national, cultural and culinary tradition. He was an IT professional who has lived in the United States for the past seven years and worked in Silicon Valley for the past three years.

Priya's mother, Radha (Ma) and her father, Nana-adhere to a conservative and traditional Telugu Brahmin caste system; they believe in arranged marriage. When Priya was sent to study computer science at Texas A\&M University when she was twenty, her parents followed some strict rules: do not eat beef, do not go overboard, save more money for dowry, after all, never marry a foreigner. Priya, who met and fell in love with Nick Collins, an American citizen currently living in San Francisco, is forced to return home. Fearing rejection, Priya wants to keep her engagement to Nick secret from her family. Upon arriving in Hyderabad, Priya was immediately affected by the sharp cultural differences between her homeland and the United States. 
Priya forgot about the garbage she grew up in, the extreme heat of summer and the chaotic surroundings. India now seems to her a troubled foreigner. Yet, despite the sense of alienation, Priya returns to her beloved grandparents' home and joins in the rich tradition of the Mango Season, along with the hottest time of the year, the wedding and monsoon seasons. During 'Mango Season', Indian women get together, harvest mangoes, gossip, laughter and wedding planning. Mango pickle is a tradition that works in the rigorous process of preparation, growing up and eating a favorite Indian dish.

Eating mangoes as a child, for Priya and her brother Nate was synonymous with happiness. After each chapter of the novel a local Indian mango recipe is shared. Examples are avocado (South Indian mango pickle), mango pappu (pea), ravaladu (sweet balls) and aloobajji (fried potatoes). A large part of the narrative is devoted to describing the brilliant interactive role of food in Brahmanical culture. While picking regular mangoes, Priya tries to reunite with her separated family.

Against the backdrop of a strict Brahmin caste, Priya's parents wonder why, at the age of twenty-seven, she could not find a suitable Indian husband. They fear that their daughter will be too old to find a suitable mate. Priya is forced to attend the bridal ceremony, "Pelli-Chupulu". To this end, Radha regularly approaches suitors whom she might meet while in her favourite city, and regularly arranges introductions with 'handsome' Indian boys. 
Ma continues to despise the lifestyle of foreigners, making it more difficult for Priya to tell her family about Nick. Priya knows she has to confess her long-held secret, and despite her heartbeat, she is sure it will affect her family. Priya is even more outraged at Aunt Lata's announcement that she is pregnant for the third time. Lata is expecting a baby boy after giving birth to two daughters earlier. Priya's grandfather wants the Brahmin boy of pure blood to continue the family line. The family's constant talk about marriage irritated Priya. In particular, her family tells her that her uncle Anand married a woman named Neelima. Neelima is from another Indian state, which makes Priya's family suspicious of their marriage. They believe that Anand was married for love rather than tradition. Priya feels more at home in the US than she does in Hyderabad.

Priya's anxiety increases when Nick stops giving her emails from States. Priya is afraid that Nick does not want to be with her anymore because of the prejudiced views of the family. Priya is further challenged when her parents introduce her to an Indian suitor named Adarsh Sharma. Priya's parents want their daughter to marry Adarsh and are excited about the idea of arranging a double wedding for Priya and her aunt Soumya.

Soumya's aunt, who has attended sixty - four brides in her life without getting married, is not at all interested in hope. But despite finding Adarsh physically attractive, Priya's love for Nick remains very strong. Nick restores his email communication and reinforces his infinite love for Priya.

In the end, Priya can no longer keep her long-held secret from her family, finally confessing that she is engaged to marry an American man. Absolutely devastated at first, Nana is the first to accept Priya's choice. Priya's family slowly comes around to shedding their prejudicial biases and provincial traditions, thereby accepting Priya's unorthodox decision. In a twisty revelation on the final page of the novel, Priya confesses that Nick is not white, but is an Afro-American man. 
Apart from Priya, there are some other important characters in this novel. Radha is the mother of the protagonist, AmulyaMalladi portrays this character as a mother who always clings to her tradition and tries to pass it on to her children. That is why there are always quarrels between Priya and her mother. Doing everything the mother makes her feel like she is in the prison. Readers can guess from reading the novel that she decided to go to the United States for higher studies. As an Indian woman, Radha has always been terribly anxious and direct about her children. Radha's view is that a woman should live a life of many trails and tribulations but Priya was exactly opposite to this view in life. She lives outside the country and has a lot of education, her views and lifestyles are very different from other Indian women who always belongs to customs and tradition. This novel shows that her hopes for her family so that they can change in their minds so that she can get rid of her thoughts and feelings. The character is also a role model for every girl living in the new modern world and how to move forward in life with own priorities and preference for selfsatisfaction with moral values.

The Mango Season of AmulyaMalladi is a novel that shows not only the steps of success but also the steps of defeat and discouragement from people who are living in the ordinary society. It is also a story about how a girl who is facing such difficulties can move forward in life and living happily. Therefore, there are many incidents in this story that give energy and vitality to the readers. In a way, the readers can see from this story how a real Indian women lives in the society who all always give the value to religion and cast as well as customs, which only these three things are valued and given importance and live for others, forgetting their own things and their own dreams. The women who lived in India made a lot of sacrifices and their daily routines are moving forward. In the early days of the Indian system, people lived as a joint family. The narrator introduces to the readers to such a family. The gist of the content is what kind of problems arise in such family, how to overcome them, 
and how to running the family forward happily and successful after all the problems with unity. Essentially there are a lot of characters in this story and that are, Nick who is born in Africa and belongs to that culture. After moving to America, Priya met Nick, fell in love and they engaged secretly. Nick was a black man. Apparently Nick does not appear in the story, but it is a character familiar to readers in many places in the novel. Nate, Sowmya, Lata, Neelima have played an important role in this story. AmulyaMalladi is mostly described her thoughts through women characters in this story, so each character represents an important Indian tradition. Therefore, the novel highlights many of the problems that exist in society, as well as a way in which the author discusses those issues and conveys many solutions and guidelines to the reader through different characters in the novel.

Arranged marriage and its consequences and in consistencies are all pointed out in the novel. Priya shares her experiences with her mother and father through different perspectives, readers can guess all the fluctuations they may have and their problems and inconsistencies. Moreover, the author has portrayed the virtues and qualities of love marriage through the character of Neelima. The couple lives happy and with dignity, but the community and family treat them as if they have done something very wrong and keep them away from the love and affection. Priya, the main character of this story, is fighting against it, because she considers it a decent way to choosing one's own husband and it is not a big mistake, and it is also self-esteem. Each of the characters in this story is highly educated, leads a reformed life, and lives by the tradition, but even if someone in the system they are living goes astray, this story depicts a way of keeping them away. Neelima's character lives in that family with a lot of such accusations. Lots of humiliations from others and it is mentioned at various stages of the story. Even knowing that she was pregnant, the character did not receive any consideration from the other characters. 
The Mango Season of AmulyaMalladi is a novel written by highlighting the extreme conditions of an Indian system which is full of such values and facts. It is also a novel that can fast compelling to read with much curiosity, which is provided from each line of story. 


\section{Works Cited}

Malladi, Amulya. THE MANGO SEASON. The Random House Publication Group.2013 www.SuperSummary.com 